\title{
First aid for fractures during accidents, catastrophes, natural disasters and terrorist acts for non-medical faculties of humanitarian and technical universities
}

\author{
Shapovalov KA ${ }^{1,2 *}$ and Shapovalova $\mathrm{LA}^{\mathbf{1}}$ \\ ${ }^{1}$ State Education Agency of Additional Professional Education of Republic of Komi, Komi Republican Institute for Development of Education, Russian Federation \\ ${ }^{2}$ State Budget Agency of Health of the Republic of Komi “Syktyvkar children`s clinic No. 3, Syktyvkar, Republic of Komi, Russian Federation
}

\section{Introduction}

\section{Fracture}

It is a violation of the integrity of the bones caused by the action of force and accompanied by damage to the soft tissues.

\section{Classification of fractures}

Fractures are:

1. Depending on whether the bone wound is related to the external environment through the wound of soft tissues and skin at the level of a bone fracture or not, all fractures are divided into two groups: closed and open. Such a division of fractures is of fundamental importance, since with open fractures there is a real danger of penetration of pathogens through the wound into the bone tissue and the occurrence of complications of a fracture with a purulent infection.

2. Depending on the localization of the fracture of the tubular bones, they are divided into diaphyseal, metaphysary and epiphyseal.

3. In the presence of a number of pathological processes (tumors, osteomyelitis, bone tuberculosis, dystrophic processes, etc.), bone strength can be significantly reduced, and a fracture occurs under the action of very little force. Such fractures are called pathological.

4. All fractures can be divided into fractures with displacement and without displacement of fragments. There are four main types of displacement: 1) in width; 2) length; 3 ) axles; 4) the periphery.

5. There are the following types of fractures:

a) transverse, when the fracture line is located more or less transversely to the longitudinal bone: they are most often found on tubular and short bones (bones of the forearm, lower leg, metatarsus, patella, calcaneus);

b) oblique, in which the fracture line goes in an oblique direction to the longitudinal bone; it is the most frequent type of fracture common to many long limb bones;

c) longitudinal, when the fracture line more or less coincides with the length of the bone. This type of fracture is most often observed when the phalanges of the fingers or the articular ends of the long bones of the limb are damaged;

d) helical, in which the fracture line resembles a screw thread. This type of fracture is observed with damage (twisting) of the long bones (mainly the lower limb, as well as the humerus); e) combined, when several lines of fractures are observed (T-shaped, W-shaped, wedge-shaped); most often occur when the so-called. intraand periarticular fractures;

f) impacted, in which one fragment is embedded ("pounded") into another.

6. Depending on how many places the integrity of the bone is broken, fractures are single and multiple.

If there are three or more fragments of bone fractures are called comminuted. Most often, these fractures are found with gunshot wounds [1-5].

After a complete fracture has occurred, and fragments of bone have formed, as a rule, they are displaced to one degree or another. The displacement of bone fragments is one of the main signs of most fractures and occurs mainly due to the contraction of muscles that attach to bones. With open fractures (in peacetime, mainly of gunshot origin), in addition to the changes described above in the damaged bone, a number of painful processes are sometimes observed. Infection that has entered the wound with open fractures leads not only to the suppuration of the soft tissues, but also to the appearance of purulentnecrotic processes in the most damaged bone, to the development of wound (fire) osteomyelitis [6-10].

\section{Fractures in children}

In childhood, in addition to the usual fractures observed in adults, there may be special fractures (fractures, subperiosteal fractures, epiphysiolysis), depending on the anatomical and physiological characteristics of children (great elasticity of the bones). When a fracture occurs, a bone fracture occurs on its convex surface, while on a concave surface the bone remains intact (fracture of the "green branch" type). A subperiosteal fracture is characterized by preserving the integrity of the periosteum and, as a result, a slight displacement of debris. In childhood and adolescence in the area of the ends of the bones there is a so-called. epiphyseal (sprout) cartilage. Sometimes

${ }^{\star}$ Correspondence to: Shapovalov Konstantin Albertovich, State Budget Agency of Health of the Republic of Komi "Syktyvkar children`s clinic No. 3 Syktyvkar, Republic of Komi, Russian Federation, Tel: + 7-8-821-2-22-32-15; E-mail: stampdu@rambler.ru

Received: February 01, 2019; Accepted: February 25, 2019; Published: February 28,2019 

universities

a fracture can occur precisely along the line of this still neostoyante epiphyseal cartilage (the so-called epiphyseolysis) [11-13].

\section{Signs of fractures}

Signs are very diverse and not always equally pronounced. They are divided into absolute, relative, local and general disorders [14-17].

Absolute signs are characteristic only for fractures and are not found for other types of damage. Any person who does not have a special medical education can determine them at the initial examination of the victim. The presence of even one absolute sign of a fracture allows the rescuer to make the correct diagnosis of a fracture on the scene without additional radiological and other studies.

The absolute signs of fractures include:

The deformation of the bone: which is caused by the displacement of debris. With non-displaced fractures, with impacted or subperiosteal fractures, deformity may be absent;

Shortening the limb: mainly depends on the longitudinal displacement of bone fragments, which occurs under the influence of muscle contraction attached to both fragments above or below them;

Pathological mobility throughout the bone: i.e. in those places where it should not normally be (a symptom of pathological mobility);

\section{Subcutaneous protrusion of debris or their presence in the wound;}

Crepitus (rubbing noise of bone debris) is usually determined in the presence of debris mobility. To detect it, it is necessary to fix the limb with one hand above and the other below the fracture and carefully move in the opposite direction. Check this symptom as well as pathological mobility need to be careful, because in a rough study, you can cause additional injury (damage to blood vessels, nerves, etc.).

The relative signs of fractures are:

1) Pain;

2) Edema (swelling) due to edema and hemorrhage in the tissue, followed by subsequent aseptic inflammation;

3) Local pain by palpation. Pain is not a specific, but a permanent sign of traumatic fracture. Soreness is determined by feeling (palpation) directly at the site of injury, as well as during loading on certain parts of the body (for example, for pelvic fractures, pain occurs in the fracture area when pressing on the pelvic wings);

4) Impairment of the function of a limb or another damaged part of the body is a fairly permanent symptom of a fracture. However, it can also be observed for other types of damage (contusion, dislocation, etc.). It should be remembered that this symptom may be absent with impacted fractures, or when there are several parallel bones (metatarsal, metacarpal), as well as a fracture of the fibula, when the tibial bone performs the main function. As a rule, they can be easily found at the fracture site.

Fractures may be accompanied by local signs (fever) and (or) general disorders (disruption of the cardiovascular system).

The final method for the diagnosis of a fracture in a hospital is radiography of damaged bones, which must be done in two mutually perpendicular projections (direct and lateral).

With bone fractures, early and late complications may occur

Early complications:
1. Bleeding: Damage to large trunk trunks are dangerous to the life of the victim. During the Great Patriotic War of 1941-1945. gunshot fractures in at least $10 \%$ of cases were accompanied by damage to the main blood vessels. Most of the dead on the battlefield due to blood loss had such combined damage.

According to various researchers, the estimated blood loss is at injury:

- Chest - up to 1.5 liters;

- Abdomen - up to 2 liters;

- Multiple fractures of the pelvic bones - 2.5-3.5 liters;

- Closed hip fracture - 1.5-3.0 liters;

- Closed hip fracture - up to 2,0 liters;

- Closed fracture of one leg - up to 1.0 liters;

- Closed fractures of both legs - up to 2.0 liters

- Closed shoulder fracture - 0.6 liters;

- Closed forearm fracture - 0.5 liters.

2. Traumatic shock: It is more often observed at gunshot fractures, especially fragmented and chipped. Late or insufficient immobilization contributes to a significant increase in the number of victims with shock.

3. Fat embolism: A rare but very serious complication is observed in case of fractures of long tubular bones in the first hours after injury as a result of the penetration of fat from the bone marrow cavity into damaged veins.

4. Anaerobic infection and sepsis: These are most common in cases of gunshot injuries to the bones of the thigh and lower leg, especially in fractured fractures. The emergence of infectious complications contribute to delayed medical care, imperfect transport immobilization, late surgical treatment.

5. Osteomyelitis: It is a frequent complication of bullet fractures of long tubular bones. The suppurative process can proceed acutely and chronically, leading to the destruction of dead bone tissue and the formation of purulent cavities.

Late complications:

1. The formation of a false joint: Persistent mobility at the fracture site is characterized by the complete cessation of the restorative (reparative) processes in the bone. It is observed after fractured and comminuted fractures of the bones of the upper limb and occurs as a result of 1) improper treatment; 2) soft tissue interposition between bone fragments; 3) development of chronic osteomyelitis; 4) hypovitaminosis.

2. Incorrectly accreted fractures: Most often occur in fractures of the hip and tibia, because the resulting shortening entails a significant violation of the function of the limb. The causes of incorrectly accreted fractures are: 1) the extent of the damage; 2) poor junk mapping; 3 ) secondary displacement of debris; 4) infectious complications; 5) mistakes made in the treatment and care of patients $[18,19]$.

\section{First (first emergency) help}

The action algorithm for detecting the victim (s) at the scene of an incident is set out in Appendix No. 2 to Order No. 477n of the Ministry of Health and Social Development of the Russian Federation dated May 04, 2012 and includes a list of first aid measures: [20-22] 

universities

1. Measures to assess the situation and ensure a safe environment for first aid: 1) determining the threats to their own life and health; 2) identification of threats to the life and health of the victim; 3 ) elimination of threatening factors for life and health; 4) the termination of the effect of damaging factors on the victim; 5) an assessment of the number of victims; 6) removing the victim from the vehicle or other hard-to-reach places; 7) movement of the victim.

2. Call an ambulance, other special services, whose employees are obliged to provide first aid in accordance with federal law or with a special rule.

\section{Determining the presence of consciousness in the victim.}

4. Measures to restore the airway and determine the signs of life in the victim: 1) drooping of the head with the chin lifted;2) the extension of the lower jaw; 3 ) determining the presence of respiration by hearing, sight and touch; 4) determining the presence of blood circulation, checking the pulse on the main arteries.

5. Measures for carrying out cardiopulmonary resuscitation until signs of life appear: 1) pressure with the hands on the sternum of the victim; 2) mouth-to-mouth artificial respiration; 3 ) Mouth-to-nose artificial respiration; 4) artificial respiration using a device for artificial respiration *

6. Measures to maintain the airway patency: 1) imparting a stable lateral position; 2) drooping of the head with a chin lift; 3) the extension of the lower jaw.

7. Measures for a survey inspection of the victim and a temporary stop of external bleeding: 1 ) a survey inspection of the victim for the presence of bleeding; 2) the elevated position of the limb; 3) finger pressure vessel in the wound; 4) finger pressure vessel over; 5) maximum flexion of the limb in the joint; 6) pressure bandage; 7) overlay harness; 8) tamponade wounds.

8. Measures for a detailed examination of the victim in order to identify signs of injuries, poisoning and other conditions that threaten his life and health, and to provide first aid in case of identifying these conditions: 1 ) conducting a head examination; 2) conducting a neck examination; 3 ) conducting a breast examination; 4) conducting a back examination; 5) conducting an examination of the abdomen and pelvis; 6) carrying out inspection of extremities; 7) application of dressings for injuries of various areas of the body, including occlusive (sealing) for injuring the chest; 8) carrying out immobilization (using improvised means, autoimmobilization, using medical devices ${ }^{*}$ ); 9) fixation of the cervical spine (manually, by improvised means, using medical products $\left.{ }^{\star}\right)$; 10) the termination of exposure to hazardous chemicals on the victim (gastric lavage by taking water and causing vomiting, removal from the damaged surface and washing the damaged surface with running water); 11) local cooling for injuries, thermal burns and other high-temperature effects or thermal radiation; 12) thermal insulation during frostbite and other effects of exposure to low temperatures.

\section{Giving the victim an optimal body position.}

10. Monitoring the state of the victim (consciousness, breathing, blood circulation) and the provision of psychological support.

11. Transfer the victim to the ambulance crew, other special services, whose employees are obliged to provide first aid in accordance with federal law or with a special rule.

In the event of fractures, special attention should be paid to the prevention of further displacement of debris and injury to the surrounding tissues, as well as complications caused by injury.

With open fractures, it is necessary to carefully carry out the actions of the rescuer action algorithm for stopping possible bleeding: 1) temporary stop of bleeding, with abundant bleeding - application of a tourniquet; 2) the imposition of an aseptic dressing on the wound; 3) pain relief; 4) transport immobilization with improvised means or standard tires.

With open fractures, it is necessary to carefully carry out the actions of the rescuer action algorithm for stopping possible bleeding: 1) temporary stop of bleeding, with abundant bleeding - application of a tourniquet; 2) the imposition of an aseptic dressing on the wound; 3) pain relief; 4) transport immobilization with improvised means or standard tires.

If there are fragments of bone in the wound, as well as foreign bodies, in the case of first aid, they should never be removed or retracted into the wound. This is done only in the hospital during surgical treatment. It is necessary to ensure that during immobilization they are not set on their own. At the same time, the limb is immobilized by improvised means or standard tires in the position in which the provider has found the victim. For the prevention of shock, an anesthetic is also administered from a syringe tube (narcotic analgesic). In winter, the victim is wrapped.

In case of closed fractures, the scope of activities of the firstperson (pre-medical emergency) rescuer actions algorithm includes: 1) anesthesia; 2) the imposition of standard transport or improvised tires [23].

\section{Tires are:}

1. Standard: 1) Cramer wire ladder: Can be modeled freely by limb;

2) Tire Dieterichs: Used for hip fractures;

3) Plastic

4) Pneumatic medical: They are removable inflatable devices from a two-layer plastic polymer shell. Purpose: operative immobilization of the extremities (hand, forearm, shoulder, foot, leg). These tires have a thermal insulation effect, ideal for winter use. Principle of action: the tire is put on the damaged segment, it is zipped, then the cavity of the tire is pumped by air through the valve. Execution options: the set is adult, the set is teenage. Each kit includes 4 tires ("long arm", "short arm", "long leg", "short leg"). Tires can be inflated by mouth (through a napkin) or by a supercharger, which is supplied separately.

5) Vacuum: Purpose: operative immobilization of the limbs, pelvis, chest and neck. These tires are ideal for immobilization of complex fractures, and especially with the displacement of fragments. Principle of action: hardening of the tire structure to the required stiffness after air is pumped out of it with the help of a manual vacuum pump. Vacuum tires are available in different combinations. Each kit includes: tires, pump, transport bag. Range of tires: arm, shin, thigh + pelvis, neck + chest.

6) Folding: Purpose: immobilization of the distal limb segments (hand, forearm, foot, tibia). These tires allow immobilization without removing the shoes from the injured leg. Principle of action: folding plates made of polymeric material along the seam form an L-shaped groove, where the limb is placed, in the opened state, the tire is fixed with powerful fasteners on velcro. There are 5 sets of tires for different ages. Each kit includes 2 tires ("arm", "leg"), a synthetic cloth bandage and a transport bag. 

universities

7) Elastic: Purpose: immobilization of the distal limb segments (hand, forearm, foot). The tire rolls into a compact roll and can be stored in any medical package. Principle of action: the tire is made of polymer material with a flexible metal frame inside. The opened tire is given the required shape, the tire is fixed to the limb with a dressing material or velcro fasteners. Execution options: adult / nursery, with fasteners / without fasteners.

2. Improvised from any available materials or objects at the scene: sticks, boards, shingles, rods, cardboard stripes, an umbrella, a spade handle, bayonets. Proper immobilization reduces pain, prevents additional damage to soft tissues, vessels, nerves and contributes to the timely healing of fractures.

\section{Rules for the imposition of transport tires}

1. The transport bus is applied so that it captures at least two joints adjacent to the fracture site, i.e. above and below the fracture; and for fractures of the humerus and femur, three joints.

2. The length of the tire is measured and modeled on the victim's healthy limb.

3. The tire is usually placed on top of clothes and shoes. To prevent tissue necrosis and reduce pain in places of bony protrusions, soft material is placed.

4. In the absence of standard tires and improvised means, the arm can be hung on a scarf, the shoulder can be pinned to the body, the injured lower limb can be pinned to healthy.

5. When providing first aid to persons who have no experience, the limb should be fixed in the position that it assumed as a result of the injury. If the assistance is provided by a medical professional, then the limbs give a functionally advantageous position. The limb must form one fixed unit with the tire.

6. To control the blood circulation in the extremities, the ends of the fingers and toes (if they are not damaged) are left free of bandages.

7. Immobilization of limbs with standard transport tires and improvised means: For fractures and significant damage to soft tissues before transportation, immobilization should be used to prevent damage to the damaged part of the body, reduce pain, prevent further damage to the tissue with bone fragments, and also prevent traumatic shock. The following types of transport immobilization are distinguished: [24]

1) Autoimmobilization (use healthy parts of the patient's body, for example, if the leg is injured, it is pinned to a healthy leg, the injured arm is pinned to the body);

2) Immobilization with improvised means (as such means you can use a stick, part of the board, a bunch of twigs or straw, an umbrella and any other objects);

3) Immobilization with standard factory-made transport tires. Transport tires are divided into fixation and distraction.

With the help of fixation tires, fixation (immobility) of the damaged part of the body is created. There are several types of fixation tires. Cramer's tire, or ladder, is made of wire. The tire can be given any shape necessary for immobilization of one or another part of the body.

The mesh tire is a mesh made from soft wire. Easy to roll. It is used mainly for immobilization of the head, forearm, hand and foot. Plywood tires are made most often in the form of splints (gutters), convenient for immobilization of the forearm and lower leg.
The mesh tire is a mesh made from soft wire. Easy to roll. It is used mainly for immobilization of the head, forearm, hand and foot. Plywood tires are made most often in the form of splints (gutters), convenient for immobilization of the forearm and lower leg.

Distraction tires. Of this group of tires, the Diterichs tire is the most common. It consists of four parts: the sole, the outer plank (crutch) of a large size; internal short strip and twist sticks with cord. It is used in case of damage to the hip, hip and knee joints, upper third of the leg.

Before applying the wire tires wrap with cotton and a bandage (soft tissue), in addition to the damage zone, the tire must fix at least two adjacent joints (above and below the injury site). And for fractures of the femur - shoulder, hip, knee and ankle joints on the injured side; humeral - radiocarpal, elbow and humeral joints on the injured side and humeral with healthy.

Clothes from the victim is not removed, with an open fracture aseptic bandage is applied through the incision in the clothes (window) only on the damaged area. The tire is adjusted to the length of the healthy limb.

\section{Features of imposing standard and improvised tires for fractures of the bones of the upper limb}

In case of fractures of the clavicle, humerus and elbow joint, the tire should start from the inner edge of the scapula of the healthy side, go through the shoulder joint, along the outer surface half bent at the elbow joint and brought to the body of the injured arm and end, slightly protruding finger tips. The brush should be bent in a fist in the dorsal flexion position. A cotton-gauze roller is placed in the armpit.

The tire is fixed to the limb with a soft bandage or kerchief. In the absence of a tire, the limb can be fixed to the body with a soft bandage, a wide bandage, or suspended on a scarf.

If the bones of the forearm are damaged, the upper level of the tire is the middle third of the shoulder, the lower ends are the ends of the fingers, and the palmar surface of the hand is facing the body or upwards. Fracture of the bone and fingers is immobilized with a wooden splint or any other material from the ends of the fingers to the upper third of the forearm, the brush is placed on the splint in the position of the back flexion with the palm down.

\section{Transport immobilization for fractures of the lower limb,} spinal column and pelvis

For transport immobilization for fractures of the femur, damage to the hip and knee joints in the lesion, use Cramer's tires or other materials. Diterichs tires are used in the first aid unit. Before applying it, the places of the bone protrusions must be covered with cotton wool or a soft material. The plantar part of the tire is fixed with a bandage to the sole of the foot (shoe). The outer rail is pushed apart and fixed in such a way that it starts from the armpit and, inserted into the metal brace in the plantar part, protrudes $10-12 \mathrm{~cm}$ behind it. The inner part of the tire is adjusted so that it rests against the groin and passes through the metal brace the plantar part, protruding behind it, is also $10-12 \mathrm{~cm}$. The final (hinged) part of it is bent at an angle of $90^{\circ}$ and put on the end of the outer plank. On the limb, the tire is fixed with two straps; with the help of a twist stick, they stretch out the plantar part of the tire. At damage of a shin and foot immobilization is made by Kramer's tires or an improvised material. The lower leg and foot must be fixed on three sides: one tire is modeled on the back of the lower leg and the foot from the tips of the fingers to the middle third of the thigh, the other two are fixed on the sides of the lower leg (outer and inner), 

universities

and their plantar part is bent as a stirrup for stronger fixation ankle joint. The foot is set at an angle of $90^{\circ}$ relative to the lower leg. Tires strengthened with soft bandages or kerchiefs.

When the victim's spinal column is damaged, carefully, avoiding bending, they put it on their backs on wooden stretchers, planks, putting a roll of clothes under the fracture site to create over-bending (hyperextension) and reducing the compression of the bodies of the damaged vertebrae. When transporting on a soft stretcher, the victim should be laid on the stomach and under the breast should be put a soft cushion of clothes, blankets, which also contributes to the extension of the spinal column. For fractures of the pelvic bones, the victim is placed on his back on a hard stretcher (board), and under the knee joints they put the clothes (blankets) rolled into a roller. The legs are bent at the knee and hip joints and fixed above the knees, which helps to relax muscles and reduce pain [25-26].

\section{Treatment methods for bone fractures}

- Gypsum bandage;

- Permanent skeletal traction;

- Osteosynthesis.

\section{Acknowledgment}

The authors express sincere love to their parents. The authors are grateful to Bychikhin NP, Orlov GA, Kucherenko VZ, Zhuravlev SM, Novikov PE, Zabin Yu.L., Dobrodeeva L.K., Sidorenkov O.K., Kuznetsova M.N., Klepikova R.A., Udalova L.S., Smolnikov L.A., Pyankov S.M., Ternovsky L.N., Batygina N.I., Rzhevskaya V.N., Duberman. LB, Lus EA, Nazarov Yu.P., Bubnov V.V., Popov O.A., Mozhayev S.A., Akhmeev V.N., Schumacher R.E. and to all anonymous reviewers for their support, valuable advice, and helpful comments.

\section{Funding}

The authors declare that there are no sources of funding for this article.

\section{Conflicts of interest}

The authors declare that there are no conflicts of interest that need to be reported in connection with the publication of this article.

\section{References}

1. Yumashev GS, Travmatologiya I, Ortopediya M (1977) Medicina 504

2. Shapovalov KA (1983) Rehabilitation period for fractures of leg bones from floating crew of the North Basin. The current state and prospects of development of marine medicine and hygiene of water transport: Materials of All-Union Conference, Moscow, 25-27 May 1983, 86-88.

3. Shapovalov KA (1983) Fractures in the structure of floating crew injuries of the northern basin. Medical and biological aspects of the study and development of the oceans: Proceedings of the IV All-Union Conference "Problems of research in the study and development of the oceans, Vladivostok, 25-28 October 1983, 7-8.

4. Shapovalov KA (1987) Socio-hygienic aspects of the transport fleet of floating crew injuries and ways to reduce it. Moscow 1987, 12633-12687.

5. Shapovalov KA (1989) Characteristics of injury with damage to the device from the bone to the floating crews of water transport. Kazan Med Zh 70: 462-463.

6. Shapovalov K (1991) Treatment of open fractures in seafarers. Bull Inst Marit Trop Med Gdynia 42: 39-41. [Crossref]

7. Shapovalov KA (1992) Injuries of the floating crew of transport, fishing and river fleets of northern pool and measures for its prevention: Abstract of Dissertation for the degree of Kandidat of Medical Sciences / Shapovalov Konstantin Albertovich, Scientificresearch Institute of Medical and Medical-Technical Information of the Research-andproduction Association "Soyuzmedinform". Moscow 1992.
8. Shapovalov KA (1994) Two Silver Medals of Shapovalov's / A. Pomortsev. Krasnoe Znamja (Independent newspaper of the Republic of Komi, Syktyvkar, Komi Republic) 1 October 1994, 188.

9. Shapovalov KA, Shapovalova LA (1995) Fractures: lecture. Syktyvkar, Komi State Pedagogical Institute 1995.

10. Shapovalov KA, Shapovalova LA (1995) Self-interacting and First Aid for injuries and accidents. Syktyvkar, Syktyvkar State University 1995.

11. Shapovalov KA (1995) Medical and social aspects of injuries of sailors of the fish fleet The problem of social hygiene, health care and the history of the medics, 17-25.

12. Shapovalov KA (1997) Social and medical issues of injury prevention fishermen manual for physicians. Moscow, Ministry of Health of the Russian Federation 1997.

13. Shapovalov KA, Shapovalova LA (2002) Fundamentals of Safety of Life: Safety and security of the population in emergency situations; self-interacting and first aid for injuries and accidents. Syktyvkar, Komi State Pedagogical Institute 2002.

14. Shapovalov KA, Shapovalova LA (2003) Fundamentals of Safety of Life: Safety and security of the population in emergency situations; self-interacting and first aid for injuries and accidents. Syktyvkar, Komi State Pedagogical Institute 2003.

15. Shapovalov KA, Shapovalova LA (2004) Fundamentals of Safety of Life: Safety and security of the population in emergency situations; self-interacting and first aid for injuries and accidents. Syktyvkar 2004.

16. Shapovalov KA (2005) Systematic approach to injury prevention of floating crew. Life and Safety 2005 Jul-Dec (3-4): 166-178.

17. Shapovalov KA, Shapovalova LA (2008) Emergency Medicine. Education of the civilian population to provide a self-, interaction-module and first aid for injuries of the head, neck, spinal table, thoracic and abdominal cavities in emergency situations. Geneva, World Health Organization, Pubrights 2008 Feb 29.

18. Shapovalov KA, Shapovalova LA (2011) National priority project "Health". Factors that have a major impact on public health. Life and Safety 2011 Jul-Dec; 3-4: 78-91.

19. Shapovalov KA (2013) Methodological approaches to teaching academic theme "Fractures" subject "First aid for injuries suffered during accidents, catastrophes and natural disasters" for humanitarian and technical universities. Shapovalov, L.A Shapovalova. Prehospital and Disaster Medicine: The Official Journal of the World Association for Disaster and Emergency Medicine. 18th World Congress for Disaster and Emergency Medicine, 23-31 May 2013, Manchester, United Kingdom. Abstracts of Scientific Papers 18th World Congress for Disaster and Emergency Medicine 2013 28(Suppl. 1): 8.

20. Shapovalov KA, Shapovalova LA (2015) Fractures and their types. Absolute, relative and local signs: Lecture. Syktyvkar, Komi Republican Institute for Educational Development, 2015.

21. Shapovalov KA, Shapovalova LA (2016) Bases of Didactics of Theme "Fractures" of Educational Module "The First (Pre-Medical Emergency) Assistance for Injuries Suffered During Accidents, Catastrophes and Natural Disasters" of Subject "Safety" for Humanitarian and Technical Universities. Life safety 2016 Jul 187: 54-61.

22. Shapovalov KA, Shapovalova LA (2016) Basics of Rendering First Medical Aid: Fractures. Syktyvkar, Komi Republican Institute for Educational Development, 10.

23. Shapovalov KA, Shapovalova LA (2017) Distance Learning Course "First Aid for Injuries and Accidents": Fractures. Syktyvkar, Komi Republican Institute for Educational Development, 15.

24. Shapovalov KA (2017) Occupational Traumatism of Members of Vessel's Crew on Fishing Fleet in the Northern Water`s Basin. Annals of Marine Science 1: 13-18.

25. Shapovalov KA, Shapovalova L (2018) Traumatism in alcoholic intoxication as marker of dependence or progressive disease on example of fishermen of the northern water's basin 19: 15 .

26. Shapovalov KA, Shapovalova PK (2019) Life Conditions of Members of Vessel's Crew of the Northern Fishing Basins, Affecting the Musculoskeletal System. Risk Factors for Occupational Traumatism. Examines Mar Biol Oceanogr 2: 548.

Copyright: (C2019 Shapovalov KA. This is an open-access article distributed under the terms of the Creative Commons Attribution License, which permits unrestricted use, distribution, and reproduction in any medium, provided the original author and source are credited. 